\title{
Enlightenment of Huizhou-style Houses on the Modern Building Design
}

\author{
Yanpeng Li \\ University of Science and Technology LiaoNing \\ Anshan, China
}

\author{
Xiang Wang \\ University of Science and Technology LiaoNing \\ Anshan, China
}

\author{
Shaojun Lin \\ University of Science and Technology LiaoNing \\ Anshan, China
}

\begin{abstract}
Huizhou-style architecture has been highly praised by architects at home and abroad. As one of the most distinctive building types of China, it has unique building types and human settlement inspired by nature, having important influence and reference significance on nowadays' building design. The formation of building is analyzed in terms of the geographical environment, building materials, economic condition and color aesthetics of Huizhou-style houses. Besides, its enlightenment on the forms and ecological development of the modern building design is also analyzed, in order to realize the inheritance and exploration of modern design via the design philosophy of the Huizhou-style houses and then seek out new development directions for the Huizhou-style houses.
\end{abstract}

Keywords-the Huizhou-style houses; characteristics; ecology; inheritance; modern building

\section{INTRODUCTION}

Huizhou culture is one of the three regional cultures in China (Chinese culture consists of Dunhuang culture, Huizhou culture and Tibetan culture). Located at the junction of Anhui, Zhejiang and Jiangxi provinces, Huizhou is in Anhui Province. In Ming Dynasty, the bamboo, wood, tea and the scholar's four jewels (writing brush, ink stick, ink slab and paper) were renowned in the world. It had splendid natural scenery with beautiful flowers. The water and the sky merged in one color. Besides, it had exceptionally developed economic civilization. Tang Xianzu, a famous opera writer during the reign of Wanli Emperor in Ming Dynasty, once described Huizhou in this way, "If one wants to make a fortune, he often seeks opportunities in Huangshan and Baiyue. I am pure and lofty in all my life but out at the elbows, I have never dreamed of going to Huizhou." It shows his admiration for the regional culture of Huizhou. Nowadays, the "integrity" and "friendship" emphasized by the General Secretary Xi Jinping are also the quintessence of Huizhou culture. The Huizhou-style architecture belongs to a predominant part of Huizhou culture and has been ardently loved by domestic and foreign master architects. It is popular in Huizhou (today's Shexian County, Xiuning County, Qimen County and Yi County in Huangshan City of Anhui Province, Jixi County in Xuancheng Province and Wuyuan County in Jiangxi Province) and pan Huizhou area. The Huizhou-style architecture is a typical example of architecture in Jiangnan area. With the distinct building style and rigorous structure, it integrates the beautiful natural sceneries of Huizhou and the quintessence of the Han culture. The planning of villages and towns, large-area space design and accurate carve of details fully embody local features. In the architecture circle, the houses, ancestral halls and memorial archways are called "three excellent things in ancient architectures of Huizhou" and are deeply admired by architects at home and abroad.

\section{FORMATION OF THE HUIZHOU-STYLE HOUSES}

\section{A. The Factors of Forming the Huizhou-Style Houses}

1) The factor of geographical environment: The formation of any architecture sect (such as the architecture sect of revivalism, the architecture sect of modernism) bases on practicality initially before design. The General Secretary Xi Jinping once addressed, "Houses are used for people to live instead of speculation". Obviously, the practicality of houses comes first. The geographical environment and conditions have determined the basic structures and forms of buildings. The local economic development and culture belong to the basic spirit of building development. The Huizhou-style houses go in the same way. The geographical environment in Anhui is one of the major factors for the formation of the Huizhou-style architectures.

According to the historical records, after the Yellow Emperor battled with Chi You (a mythological warrior) in ancient times, some defeated people came to ancient Huizhou area and settled down here to live long and prosper. However, the textual research shows Huizhou area in history was the settlement of ancient Yue people. Geographically, it has high mountains and lofty hills, undulating hills. The water and the sky merge in one color. Moreover, with a small area, the land is narrow at the meantime. Therefore, the ancient Yue people first lived in nests and then in "handrail-type" houses, the framework of which consisted of bamboos and woods and the 
roof of which was covered by thatches. It wasted time and energy and had poor stability.

Furthermore, the integration of central plain culture and ancient Shanyue culture is also represented through buildings. The quadrangle courtyard in Central Plains gradually evolves into "parvis-type" and "three hidden rooms" [2]. Different from modern times, the Anti-Japanese War of Chinese nation mainly happens in mountainous area that becomes the main battlefield of anti-Japanese guerrilla forces. While in ancient times, few wars occurred in mountain areas, so a lot of people settled in Huizhou. The Huizhou-style architectures at early stage remained to be "handrail-type". The first floor was low and small, and the major function was damp-proof. These buildings had spacious upstairs halls that played the important role in people's communication. Afterwards, people in Central Plains settled in. With a large number of people and a small area, the place was suitable for the construction of buildings. The buildings were near the mountain or based on terrain because of the influence of geographical environment. All in all, it was inspired by nature.

2) The factor of building materials: Huizhou has numerous mountains and undulant hills and plentiful forest resources, so local residents have built plenty of wooden houses by local materials. Local houses and ancestral halls are made from thick and strong woods. People called the beams "wax gourd beam". It is also called "moon beam" because it resembles lying new moon. The houses are magnificent and have splendid uprights that are square and round appropriately. It is not cumbersome after upward treatment. [4] Wood carving is included in the four excellent things in Huizhou. You will feel yourself in the place full of art. Wood carvings can be found everywhere as if you can hear the passage of time. The exquisite scenes make people too delighted to leave. The wood carvings involve mountains, rivers, trees, grains and geometric features. The windows of ancient houses in Huizhou cannot be opened outwards. The window sashes have hollowed-out floriated carvings for the inlet of light and ventilation. The lower edges of window sashes are carved by slab. Breast board exists below one third of the window and is called Lan Chuang Yi by local people. It can hinder vision and wind and rain from the parvis and doesn't influence lighting, embodying the wonderful workmanship of engravers in ancient Huizhou.

The indoor materials of the Huizhou-style architectures are also quite exquisite. In terms of timber components, the pillar, purlin and roof boarding are mainly made from cedars. Families with good economic condition use ginkgos and pines. Cedars have soft and delicate characters with fragrance, straight texture, easy processing and strong rot resistance. Most importantly, it will not be damaged by white ants. Ancient artisans learned these characteristics from practice. The surface of pillars is not treated by base coat and coated with oil paint, so the beam and floor are made from masson pines, which are waterproof, elastic with thick structures and extensive use. With regard to the outdoors, the outer wall surface is smeared with chalk. Chalk is a kind of limestone, the main component which is calcium carbonate. It is soft and fragile but cheap and fine as the coating of outer walls. Besides, it is radiation protection and thermal insulation as well as protects timber frames when it's rainy and wet. For stones, the bluestone in Yi County is the most famous. With the main component of limestone, the stone is hard and exquisite and becomes very smooth after polishing, mainly used for ancestral halls and memorial archways. Red granite from Shexian County and Xiuning has relatively soft texture and can be used to make stone base and plinth. When the safety performance and drainage function of brick walls strengthen and indoor planks become more damp-proof, the building types evolve. The first floor is spacious and the upstairs is simpler. Furthermore, another feature of the Huizhou-style architecture embodies in: the walls are often treated with lime. Because southern Anhui was not damp relatively and called foul atmosphere in ancient times, it required damp-proof treatment. The lime on the wall space contributes to the absorption of moisture in the air to dry so that the wall will not damaged by rainwater. Houses with timber structure in mountainous areas are troubled by fire, so Ma Tau Wall appears to prevent fire hazard. The early Huizhou-style architectures belong to the common products of both indigenous people and immigrants [3].

3) The factor of economic condition: In ancient China, salt, horse, iron and tea belonged to the country and were controlled by the government until Ming Dynasty. The border crisis forced the government to transport large numbers of military supplies. The government can transport more than that conveyed by merchants. The government will certainly transport it to the battlefield but it costs too much. Therefore, in Ming Dynasty, the state-owned enterprises withdrew and private-owned enterprises entered. Merchants obtained the management right of salt, silk, horse and tea. Tremendous business groups occurred, with Shanxi merchants and Huizhou merchants most famous. Huizhou merchants began to rise sharply from that moment forward and had lasted for more than 300 years in the business circle of China. Waterway became the best choice in ancient times when the land transportation was inconvenient. In six counties of ancient Huizhou Prefecture, people in Qimen first went outside home, and Qimen refers to today's Qimen County. Water in Qimen flows into Poyang Lake by way of Fuliang and flows to all parts of the country through the Yangtze River. [6]

The ancients had a saying, "Poverty gives rise to the desire for change", which was reasonable indeed. People were crowded in ancient Huizhou, which had narrow land unsuitable for plantation. Ancient Huizhou people's idea of going out for survival has been inherited in many generations. Doing business has become the major activity of Huizhou people. In Tang Dynasty, the tea in Huizhou was exported from Fuliang. After Lin'an became the capital of the Southern Song Dynasty, water transport was developed in Huizhou with favorable geographical position. After the middle period of the Ming Dynasty, Huizhou merchants were at a period of great prosperity. The number and the range of activity of merchants were in the first place in the business circle. At that time, the Huizhou merchants' range of activity was very extensive. 
They can be seen from south to north even nationwide. A proverb "It cannot be called town without Huizhou merchants" was spread even in the middle and lower reaches of Yangtze River. Eight general chambers of salt merchants from north and south of Huaihe River appeared in Qing Dynasty. There were four Huizhou merchants. Emperor Qianlong sighed with emotions that "Salt merchants are richer than me" when he visited regions south of the Yangtze River. Huizhou merchants who made a fortune in other places "built ancestral hall, high buildings, gardens and memorial archways" after returning to their hometown, making the countryside change enormously.

Besides, the business groups in Huizhou "regarded Confucianism superior to business" and "prospered business via Confucianism". Therefore, they extensively made friends with feudal officials. Some merchants had high literature accomplishment. Some people catered to their pleasure and collected calligraphies and paintings and built gardens for conversation. Some merchants even invited painters and architects at that time to participate in the design. Therefore, the buildings had unique styles, reasonable layout and exquisite decoration and were inspired by nature. Besides, the delicate wood carvings and stone carvings made the Huizhoustyle architectures practical with rich architectural language.

\section{B. Color Aesthetics of the Huizhou-Style Houses}

The building materials of the Huizhou-style houses are abundant. Huizhou teemed with cedars, pines and weeping cypresses and natural paints like China wood oil and law lacquer. Stones suitable for firing bricks and tiles as well as lime-stones existed in high mountains and lofty hills. Under this geographical environment, the Huizhou-style houses are built by black bricks, timbers, tiles and limes. The footing of wall is made of red granites. The outer wall is built by grey tiles and brushed by chalk and the seam of wall is filled with plaster. The pillar, beam and floor as well as internal partition are made of timber. Huizhou has subtropical monsoon climate that is moist. For drainage and damp proofing, the outer wall is built by bricks and brushed by plaster. The Huizhou-style houses have white wall, black tile and grey bricks. Black, white and grey become the dominant hues of it.

In ancient China, the use of color was stipulated strictly according to hierarchy. Yellow became exclusive for imperial households. Temples of imperial palace used yellow and red. Red, cyan and blue were used by palaces of princes and eunuchs. Common people were only allowed to use black, white and grey in building. So the Huizhou-style houses are not exception. The simple hues of black, white and grey for the black tiles and white walls had sharp contrast when people looked at it from a distant place. With the passing of time, the white wall becomes mottled. The houses are near the mountain and by the river and echo with pavilions. The dark grey tiles present the virtual and actual scene as well as the white and grey scene under the sunset. The picture with "bridge, river and home" heaves in sight.

\section{ENLIGHTENMENT OF THE HUIZHOU-STYLE HOUSES ON} DESIGN

\section{A. Enlightenment of the Huizhou-style Houses on Shape Design}

Ma Tau Wall is the most characteristic appearance of the Huizhou-style architectures. The architectural model means raising the gable on one side of the house to remain above the roof or ridge. Meanwhile, the roof is treated via horizontal line. To effectively avoid the large altitude difference between the gable edge and the roof, they use downward grade. It saves materials and makes the houses seem undulant and wellarranged. The wall is more artistic than general wall. Ma Tau Wall has many forms including magpie tail, Yindou, Zuowen, cod fish and tiangou. The gold seal type embodies the owner's pursuit of "reading and being an official". Horses belonged to high-ranking tool for riding instead of walking in ancient times and had played an important role in wars. Therefore, the ancients ardently loved horses and regarded it as a mascot. Idioms related to horse such as "success immediately upon arrival" and "take the lead" revealed people's love for horse. It may be the reason why it is called Ma Tau Wall.

The impression left by the appearance of the Huizhou-style houses is: grey tile, white wall and black wall side. The style exists in the houses of common people, houses with large courtyard, ancestral halls and temples. It is represented by the texture of materials instead of paintings. The gatehouses and gate covers are not painted. Sash and timber door retain wooden texture. Natural beauty can be found everywhere. It resembles a landscape painting with black alternating with white and is clear at a glance. It makes people feel Laozi's and Zhuangzi's philosophy. Besides, the representation of the tao way follows nature makes it too profound to be understood. Although the construction of modern urban communities vigorously advocates rich colors and diversified styles, the basic architectural forms are modern and concise. Dense colors and contrasting colors appear on individual buildings and commercial buildings. Most still likes veiled and plain style. Doors and furniture without paint are advocated in decoration design. Furniture with wooden texture is extensively used. The application of artificial quartz stone also embodies the continuity of idea in the Huizhou-style houses with great vitality. In some communities, pavilions, terraces and towers and some wooden trestles are built on the community square in the area for public activities. Some meaningful cultural modeling or gates with ingenious design are built. Moreover, fresh current and artificial hills are used to make up for the details lost in the era full of high-rise buildings.

\section{B. Enlightenment of the Huizhou-style Houses on Ecological Design}

The Huizhou-style houses are very simple and neither as colorful as gardens in Suzhou and Hangzhou nor as dark as buildings of official residence. It forms elegant artistic beauty by virtue of exquisite carving. The idea that the Huizhou-style architectures are not luxury is also embodied in modern decoration. The modern scientific and technological development makes us concentrate efforts on details to show aesthetic taste. The houses indeed make people with different 
backgrounds and identities feel at ease and experience the artistic conception of following the natural world. The construction planning of historic villages in Huizhou makes it keep cool in summer and keep warm in winter. People pursue "the unity of nature and man" between dwelling space and environment. Inspired by the architectural form, modern architects can make the best of natural environment and sunlight and reduce the dependence of houses on resources. Active solar energy collector can be used to obtain domestic hot water. Solar energy combines with construction greening. The temperature of outer wall with Boston ivy will drop seven degrees in summer. New-type materials such as rock wool and aerated concrete can be applied to the roof. Roof garden can be built to beautify the environment and achieve thermal insulation. Buildings and streets face the sun as far as possible. Airtight windows and pvc plastic energy-saving windows can collect dust and reduce noise as well as reduce energy consumption. Meanwhile, sanitary sewage processor is provided outdoors to make water resources used in outdoors greening. With global warming and continuous consumption of non-renewable resources, the exploration of ecological environment design and sustainable development of modern architectures will be important subject.

\section{CONCLUSION}

Many ideas of today's architects and designers will be influenced by creative design, social environment, new materials and advanced processes. Meanwhile, designers can thoroughly think how to better continue the wisdom of people in ancient Huizhou and get rid of the stale and bring forth the fresh. The traditional Huizhou-style houses respect natural landscape and are located near the mountain and by the river. The appearance with integrity is full of aesthetic feeling. Distinctive Ma Tau Wall is in the form that the high wall covers up horse's head and lifted legs. Green hills and blue waters and grey tiles are simple, delicate and pretty. The exquisite detail decoration unveils the yearning of people in ancient Huizhou for beautiful life and the matchless workmanship of technicians and craftsmen. Modern architectural design can use for reference and organically integrate the style of the traditional Huizhou-style houses that follow nature and modern buildings. The inspiration on design can be applied to modern design via new forms. All designers need to meet people's demands for aesthetic culture and create buildings with historical symbols, ecological homestead, architectural language and green ecology and sustainability through high technology that changes with each passing day. It is also the mission of each architect in new times.

\section{REFERENCES}

[1] Zhou Lei. Application and Research of Elements in the Huizhou-style Houses in Modern Building, Apr.1, 2009

[2] Chen Ansheng. Discussion on Several Conditions for the Formation of the Huizhou-style Houses - the Inheritance and Promotion of the Huizhou-style Houses, Collected Papers of Seminar on the Culture of China's Huizhou-style Houses, Mar.15, 2008

[3] Miao Junsheng. Characteristics of the Huizhou-style Houses, Modern Sciences, Mar.23, 2009
[4] Feng Wei. Research on Elements of the Settlement with Traditional Huizhou-style Houses, China Ancient City, Sept.5, 2011

[5] Xue Shengyan. The Relationship Between the Regional Culture of Jingdezhen and the Sightseeing Streets for Tourism and the Influence. Shanxi Architecture, Jan.10, 2012

[6] Chen Ansheng. Discussion on Several Conditions for the Formation of the Huizhou-style Houses - the Inheritance and Promotion of the Huizhou-style Houses, Collected Papers of Seminar on the Culture of China's Huizhou-style Houses, Mar.15, 2008 